\title{
A Randomized Crossover Trial Comparing Patient Preference for Mandibular Complete Dentures Made with Two Different Techniques: A Short-Term Follow-Up
}

\author{
Greta A.V.M. Geerts, BChD, PDD, MChD, $\mathrm{PhD}^{1}$
}

\begin{abstract}
Purpose: The objective of this trial was to compare short-term patient preference for two mandibular complete denture (CD) fabrication techniques: neutral zone (NZ) and conventional

(CV). Materials and Methods: A prospective, within-subject, randomized crossover trial was performed on a sample of 37 edentulous patients with complete denture experience. Two new sets of CDs were made for each patient, one set with a CV and one with a NZ mandibular denture. After consecutively wearing each set for at least 2 months after the last adjustment visit, patients indicated their preference (CV, NZ, or none). Associations and comparisons were made using the generalized linear model (GLM) and Fisher exact test between preference and sex, age, period of edentulousness, tissue quality, prosthodontic diagnostic index (PDI), and oral health-related quality of life (OHRQoL) differences of the two interventions assessed using the 20-item oral health impact profile (OHIP-20). Significance was determined at $P=.05$.

Results: A total of 15 (40\%) patients preferred NZ, 8 (22\%) preferred CV dentures, and 14 (38\%) had no preference. Although more women preferred NZ over CV dentures (50\% versus $27 \%)$, difference in preference according to sex was not significant $(P=.359)$. Neither was difference in preference and PDI scores significant $(P=$.603). Preference could not be strongly associated to period of edentulousness, age, tissue scores, and differences in OHIP-20 scores $(P>$.05), except for OHIP-20 scores and NZ preference $(P<.001)$. Better fit, comfort, and eating were reasons patients preferred a type of denture. These reasons were identified for both types of denture. Appearance and speech were not identified as reasons for a particular preference. Conclusion: Based on preference expressed by patients, there is no difference between NZ and CV mandibular dentures. Denture preference could not be related to patient variables over the study's time frame. Int J Prosthodont 2017 (7 Pages). doi: 10.11607/ijp. 5097
\end{abstract}

T he neutral zone (NZ) in complete dentures (CDs) is defined as "the potential space between lips and cheeks on the one side, and the tongue on the other; that area or position where the forces between the tongue and cheeks and lips are equal." 1 The boundaries of this space comprise the third, or polished, surface of a denture in contrast to the intaglio and occlusal surfaces, and is regarded as a significant contributor to prosthesis stability. ${ }^{2}$

Increased life expectancy and multimorbidity of aging populations suggest an ongoing need for simplified CD treatment protocols in spite of recent advances in implant therapy. ${ }^{3,4}$ Nonetheless, the profession is yet confronted with diverse and numerous fabrication techniques that lack high-level scientific

\footnotetext{
${ }^{7}$ Associate Professor and Senior Lecturer, Department of Restorative Dentistry, Faculty of Dentistry, University of the Western Cape, Tygerberg, South Africa.
}

Correspondence to: Dr Greta A.V.M. Geerts, Department of Restorative Dentistry, Faculty of Dentistry, University of the Western Cape, Private Bag XI, Tygerberg 7505, South Africa.Email: ggeerts@uwc.ac.za

(C)2017 by Quintessence Publishing Co Inc. evidence to justify their routine use. Employing the NZ concept for mandibular CD fabrication remains a popular educational and practice tenet in the prosthodontist community. However, few clinical trials have reported patient-based outcomes (PBO) that test the merits of the NZ approach. ${ }^{5-7}$ Their results suggest patient preference for NZ dentures. However, except for quality of denture-supporting tissues, none of these trials assessed the influence of patient variables on preference.

Successful wearing of $\mathrm{CDs}$ requires neuromuscular skills for prosthetic adaptation, and later-life edentulism is believed to be associated with diminished adaptive capacity. ${ }^{8}$ Consequently, clinical techniques that are believed to enhance prosthesis stability would appear to be logical recruits for managing the edentulous mandible, especially in the presence of advanced residual ridge resorption. Could NZ mandibular dentures be considered better quality than CV mandibular dentures, and have a positive effect on treatment outcome? Do patient variables affect PBOs when comparing NZ or CV denture preference? To answer these questions, a prospective, within-subject, randomized crossover trial was performed comparing 
Table 1 Inclusion and Exclusion Criteria

\begin{tabular}{ll}
\hline Inclusion criteria & \multicolumn{1}{c}{ Exclusion criteria } \\
\hline Aged $40-85$ y & Symptoms of TMD \\
Edentulous & Oral pathology \\
Prior denture experience & Parafunction \\
Requiring new dentures & Severe xerostomia \\
Able to read, understand and respond to the OHIP-20 & Orofacial motor disorders \\
instrument (in English) & Severe oral manifestations of systemic disease \\
Informed consent given & Psychologic or psychiatric conditions that could influence \\
Ability to attend 9-10 visits & response to treatment \\
& Wanting dental implants \\
\hline
\end{tabular}

OHIP-20 $=20$-item oral health impact profile; TMD $=$ temporomandibular disorder .

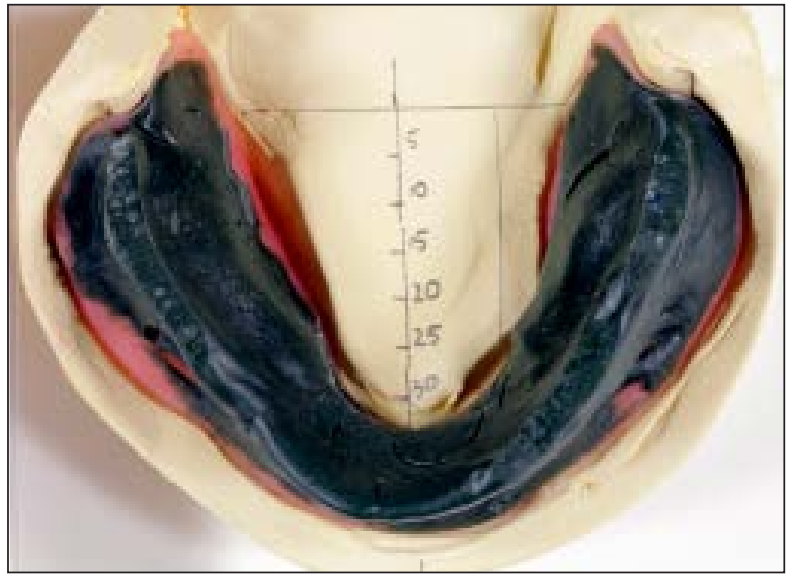

Fig 1 Neutral zone impression using resin base and impression compound rim.

patient preference for NZ and CV dentures. The first null hypothesis was that there is no patient preference for NZ or CV mandibular CDs. The second null hypothesis was that patient variables are not associated with preference.

\section{Materials and Methods}

The trial proposal was registered by the Research Committee of the University of the Western Cape (number 11/1/49). The trial was done at the Tygerberg Oral Health Centre, a training and service-rendering site for the Faculty of Dentistry. All clinical, technical, and research work was performed by the same individual. A total of 39 patients with complete denturewearing experience were selected and screened for participation in the trial. Patient inclusion and exclusion criteria are given in Table 1.

Two sets of CDs were constructed for each patient. One mandibular denture was made following anatomical criteria; the second was made following the NZ concept (Figs 1 and 2). Figure 3 is a diagrammatic illustration of the resulting shapes of the two types of mandibular dentures. The maxillary

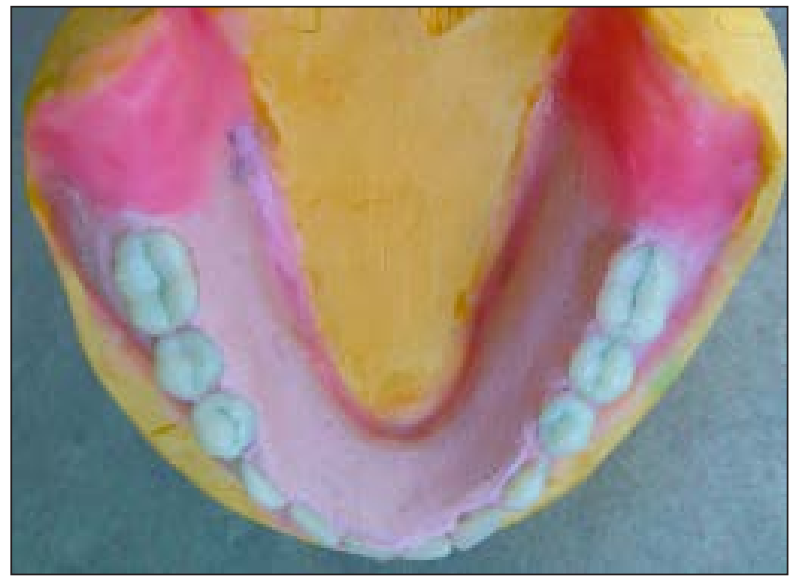

Fig 2 Verification impression of facial and lingual surfaces of wax trial denture sealed on definitive cast before flasking.

dentures were made to be identical for both sets by using silicone templates on the same articulated casts. Patients were assigned to receive one of the two treatments first by means of random draw from a container holding 40 tickets coded with equal numbers of "CV" and "NZ."

Each set of CDs was worn for at least 8 weeks after the last recall visit. When the second set was delivered, the first set was withheld from the patient. Patients were blinded to the type of dentures worn and were not informed on the nature of the difference between the two sets of CDs. General biographic and sociodemographic data and denture-wearing history were collected. Mandibular denture-supporting tissue was scored according to the criteria given in Table 2. Edentulousness condition was scored for each patient according to the Prosthodontic Diagnostic Index (PDI). ${ }^{9}$ Oral health impact profile questionnaires with 20 items (OHIP-20) were completed after each 8 -week period of denture wearing to establish oral health-related quality of life (OHRQoL) for each treatment intervention. At the end of the trial, preference had to be expressed (CV, NZ, or none). Patients were also asked to explain their preference. 


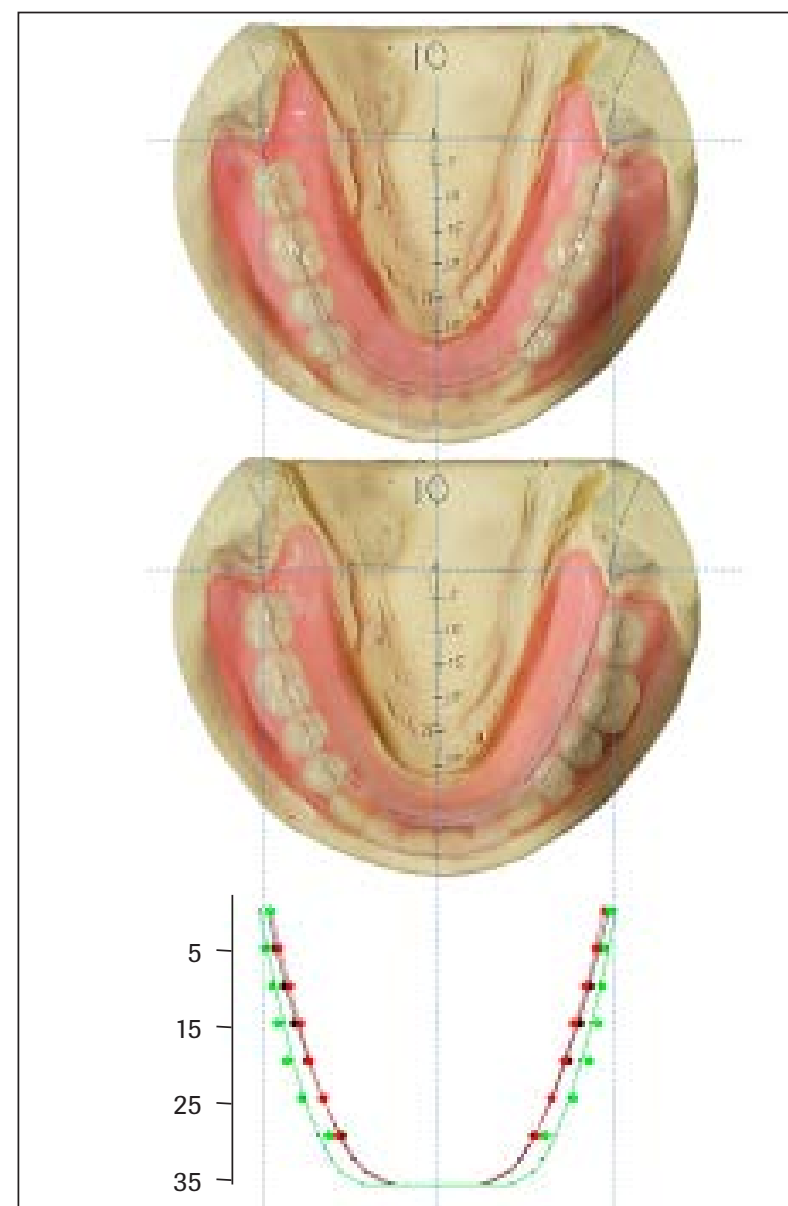

Fig 3 Standardized digital layers of definitive cast over CV (top) and NZ (middle) wax trial dentures. Diagrammatic illustration of ridge crest (black line), CV denture arch (red line), and NZ denture arch (green line) using a parabola.

A power analysis was done after piloting a sample of four patients, using one-sample $t$ tests. A clinically meaningful mean difference of OHIP-20 scores (CV-NZ) was estimated to be between 5 and 10. The required sample size was 34 . The pilot sample was added to the trial.

Standard clinical prosthetic procedures for fabricating dentures were followed. Sequence of visits and materials used are shown in Table 3. For the CV mandibular denture, the posterior mandibular teeth were arranged according to a modified Pound triangle. ${ }^{10}$ For the NZ mandibular denture, the technique described by Cagna et $\mathrm{al}^{10}$ was followed. A lingualized occlusion without compensating curves was used for both denture sets.

Differences in preference were analyzed using Fisher exact test. Associations of denture preference with patient variables (age, sex, denture experience, tissue scores, $\mathrm{PDI}$ ) were made by means of regression analysis using generalized linear models (GLMs). For all statistical tests, significance was determined at $P=.05$.

No important changes to the methods were made after the commencement of the trial.
Table 2 Mandibular Supporting Tissue Scoring Criteria

\begin{tabular}{lclc}
\hline Bone resorption & Score & $\begin{array}{c}\text { Tissue } \\
\text { resilience }\end{array}$ & Score \\
\hline Extreme (flat) & 1 & Flabby & 1 \\
Severe (V-shaped) & 2 & Resilient & 2 \\
Moderate (U- to V-shaped) & 3 & Firm & 3 \\
Little (U-shaped) & 4 & & \\
\hline
\end{tabular}

Table 3 Sequence of Visits and Materials Used

\begin{tabular}{|c|c|}
\hline Visit & Procedure and materials \\
\hline 1 & $\begin{array}{l}\text { Primary impressions with edentulous stock trays (Eezitray, } \\
\text { Wright Health Group); irreversible hydrocolloid impression } \\
\text { material (Blue Print, Dentsply De Trey) }\end{array}$ \\
\hline 2 & $\begin{array}{l}\text { Definitive impressions with custom-made trays (Megatray, } \\
\text { Megadenta), border molding with modeling plastic } \\
\text { impression compound (Greenstick, KerrHawe), and zinc } \\
\text { oxide eugenol impression paste (SS White, SS White) }\end{array}$ \\
\hline 3 & $\begin{array}{l}\text { Jaw registration with wax record rims (denture modeling } \\
\text { wax sheets, Kemdent) }\end{array}$ \\
\hline 4 & $\begin{array}{l}\text { Try-in of the CV wax trial denture; neutral zone impression } \\
\text { using modeling plastic impression compound rim on resin } \\
\text { base (Rapid-repair, Dentsply) according to Cagna et al }{ }^{10}\end{array}$ \\
\hline 5 & $\begin{array}{l}\text { Try-in of NZ wax trial dentures; verification impressions of } \\
\text { facial and lingual surfaces of mandibular dentures using zinc } \\
\text { oxide eugenol impression paste according to Cagna et al }{ }^{10}\end{array}$ \\
\hline 6 & Clinical remount and delivery of first set of dentures; recalls \\
\hline 7 & $\begin{array}{l}\text { Clinical remount and delivery of second set of dentures; } \\
\text { recalls }\end{array}$ \\
\hline
\end{tabular}

$\mathrm{NZ}=$ neutral zone; $\mathrm{CV}=$ conventional.

\section{Results}

Patient allocation and retention is shown in the CONSORT flow diagram (Fig 4).

Total number, preference according to sex, and association between denture preference and sex is shown in Table 4. Using Fisher exact test, no significant difference was found in preference by sex $(P=.359)$. Using only the data for $\mathrm{CV}$ and NZ preference (excluding patients who had no preference) also did not show a significant difference in preference by $\operatorname{sex}(P=.195)$.

Mean summary OHIP-20 scores for CV and NZ dentures were 14.53 and 14.21, respectively. Preference for a denture type matched OHIP-20 score differences 23 times (a difference OHIP-20 NZ minus CV of $<7.5$ was considered clinically insignificant, based on the power analysis). On one occasion, a patient preferred the CV denture when the OHIP-20 score was in favor of the NZ dentures; for the remaining 13 occasions, there was either no preference with a difference in OHIP20 scores or no difference in OHIP-20 scores with a particular preference. The relationship of denture 


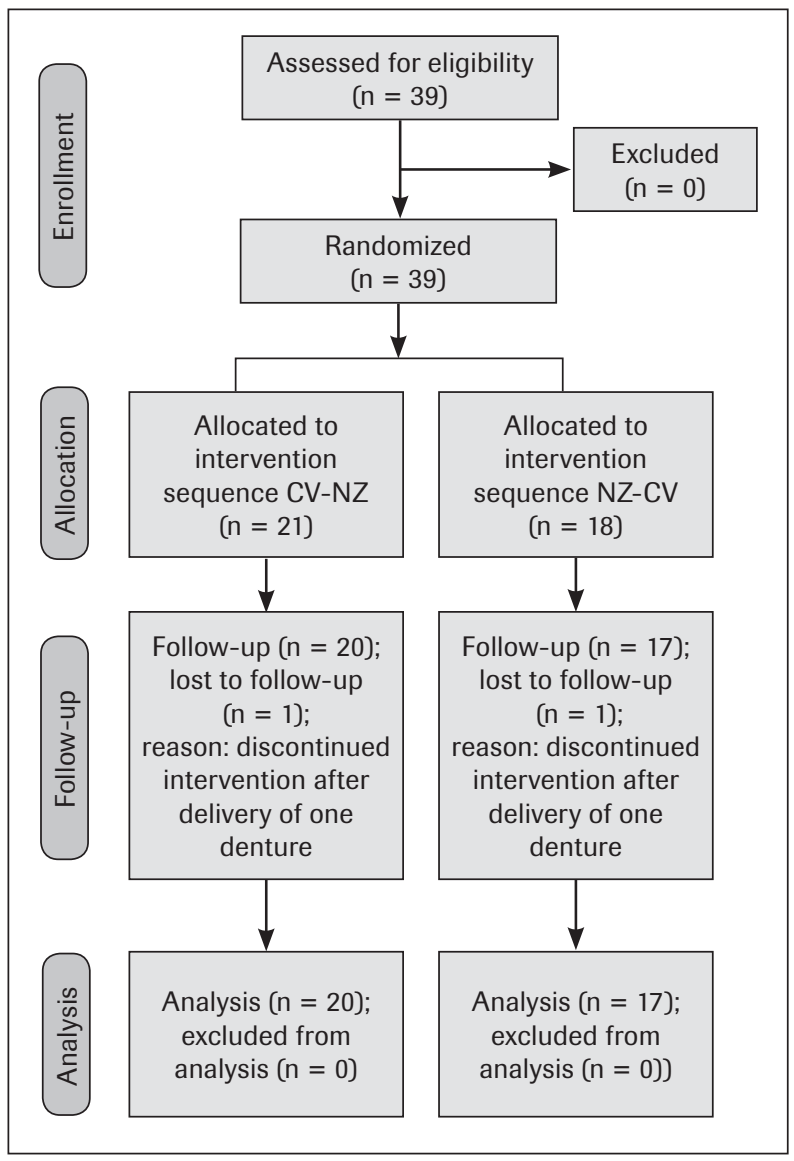

Fig 4 (Left) CONSORT flow diagram.

Fig 5 (Below) Box-and-whisker plot for denture preference versus difference in OHIP-20 scores of CV minus NZ dentures. OHIP-20 = 20 -item oral health impact profile; $\mathrm{CV}=$ conventional denture; $\mathrm{NZ}=$ neutral zone denture.

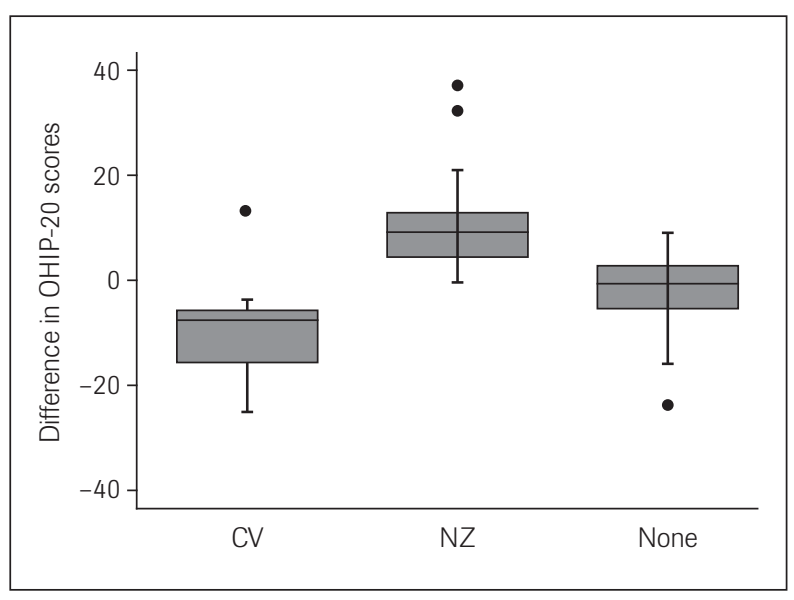

Table 4 Denture Preference by Sex

\begin{tabular}{lccc}
\hline \multicolumn{1}{c}{ Preference } & CV & NZ & None \\
\hline Men $(n=15)$ & $4(27 \%)$ & $4(27 \%)$ & $7(46 \%)$ \\
Women $(n=22)$ & $4(18 \%)$ & $11(50 \%)$ & $7(32 \%)$ \\
Total $(n=37)$ & $8(22 \%)$ & $15(40 \%)$ & $14(38 \%)$ \\
\hline CV = conventional denture; NZ = neutral zone denture.
\end{tabular}

Table 5 GLM Analysis of Denture Preference and Difference in OHIP-20 Scores

\begin{tabular}{|c|c|c|c|c|c|c|c|c|c|}
\hline \multirow{2}{*}{$\begin{array}{l}\text { Preference } \\
\text { CV }\end{array}$} & \multirow{2}{*}{$\frac{n}{8}$} & \multirow{2}{*}{$\begin{array}{c}\text { Mean } \\
-8.94\end{array}$} & \multirow{2}{*}{$\frac{S D}{11.31}$} & \multicolumn{6}{|c|}{ GLM } \\
\hline & & & & Coefficient & SE & z & $P>|\mathrm{z}|$ & \multicolumn{2}{|c|}{$[95 \% \mathrm{Cl}]$} \\
\hline$N Z$ & 15 & 10.87 & 11.04 & 19.904 & 4.590 & 4.31 & $.000^{*}$ & 10.809 & 28.800 \\
\hline None & 14 & -3.45 & 9.35 & 5.485 & 4.646 & 1.18 & .238 & -3.621 & 14.592 \\
\hline Constant & & & & -8.938 & 3.707 & -2.41 & .016 & -16.202 & -1.673 \\
\hline
\end{tabular}

$\mathrm{CV}$ denture preference was used as reference.

$\mathrm{GLM}=$ generalized linear model; $\mathrm{CV}=$ conventional denture; $\mathrm{NZ}=$ neutral zone denture; $\mathrm{SD}=$ standard deviation; $\mathrm{SE}=$ standard error; $\mathrm{Cl}=$ confidence interval; $\mathrm{z}=$ standard score.

*Statistically significant.

preference and difference in posttreatment OHIP-20 scores is shown in Fig 5. A negative CV-NZ OHIP20 value means that $\mathrm{CV}$ had a more positive impact on OHRQoL; the difference would be positive if the NZ denture had a more positive impact on OHRQoL. Using the GLM, the results of the relationship of preferences with OHIP-20 differences are given in Table 5 . There was no close association of OHIP-20 with preference, except for NZ preference, with a coefficient of 19.904 , which was statistically significant $(P<.001)$.

Mean mandibular tissue score was 4.21 (range: 2-7). Using the GLM, the results of the relationship of denture preference with mandibular tissue score are given in Table 6. The tissue score for people who preferred the NZ denture was 0.4 higher; for those who had no preference it was 0.143 higher. This was not statistically significant $(P>.05)$.

The PDI scores are given in Table 7. Seventy percent of patients were in class III and IV (most challenging). Fisher exact test did not show a difference in denture preference according to PDI scores $(P=.603)$.

Mean age of patients was 62.3 years (range: 47-85 years). Table 8 shows the results of the GLM relating denture preference with age. None of the relationships were statistically significant $(P>.05)$.

Mean period of edentulousness was 30.9 years (range: 1-60 years). Table 9 shows the results of the 
Table 6 GLM Analysis of Denture Preference and Mandibular Tissue Score

\begin{tabular}{|c|c|c|c|c|c|c|c|c|c|}
\hline \multirow{2}{*}{$\begin{array}{l}\text { Preference } \\
\text { CV }\end{array}$} & \multirow{2}{*}{$\frac{n}{8}$} & \multirow{2}{*}{$\begin{array}{c}\begin{array}{c}\text { Mean } \\
\text { mandibular } \\
\text { tissue score }\end{array} \\
4.0\end{array}$} & \multirow{2}{*}{$\begin{array}{r}\text { SD } \\
1.69\end{array}$} & \multicolumn{6}{|c|}{ GLM } \\
\hline & & & & Coefficient & SE & z & $P>|z|$ & \multicolumn{2}{|c|}{$[95 \% \mathrm{Cl}]$} \\
\hline $\mathrm{NZ}$ & 15 & 4.4 & 1.64 & 0.400 & 0.685 & 0.58 & .559 & -0.943 & 1.743 \\
\hline None & 14 & 4.1 & 1.41 & 0.143 & 0.938 & 0.21 & .837 & -1.217 & 1.503 \\
\hline Constant & & & & 4.000 & 0.553 & 7.23 & .000 & 2.915 & 5.085 \\
\hline
\end{tabular}

CV denture preference was used as reference.

$\mathrm{GLM}=$ generalized linear model; $\mathrm{CV}=$ conventional denture; $\mathrm{NZ}=$ neutral zone denture; $\mathrm{SD}=$ standard deviation; $\mathrm{SE}=$ standard error; $\mathrm{z}=$ standard score; $\mathrm{Cl}=$ confidence interval.

Table 7 Frequency and Percentage of PDI Scores by Preference

\begin{tabular}{lcccc}
\hline & \multicolumn{3}{c}{ Denture preference (n [\%]) } & \\
\cline { 2 - 4 } PDI & CV & NZ & None & Total (n [\%]) \\
\hline I & $1(12.50)$ & $2(13.33)$ & $2(14.29)$ & $5(13.51)$ \\
II & $1(12.50)$ & $3(20.00)$ & $2(14.29)$ & $6(16.22)$ \\
III & $1(12.50)$ & $5(33.33)$ & $7(50.00)$ & $13(35.14)$ \\
IV & $5(62.50)$ & $5(33.33)$ & $3(21.43)$ & $13(35.14)$ \\
Total & $8(100.0)$ & $15(100.0)$ & $14(100.0)$ & $37(100.0)$ \\
\hline
\end{tabular}

$\mathrm{PDI}=$ Prosthodontic Diagnostic Index; CV = conventional denture; NZ = neutral zone denture.

Table 8 GLM Analysis of Denture Preference and Mean Age of Patients

\begin{tabular}{|c|c|c|c|c|c|c|c|c|c|}
\hline \multirow{2}{*}{$\begin{array}{l}\text { Preference } \\
\text { CV }\end{array}$} & \multirow{2}{*}{$\frac{n}{8}$} & \multirow{2}{*}{$\frac{\text { Mean age }(y)}{59.1}$} & \multirow{2}{*}{$\frac{\mathrm{SD}}{8.114}$} & \multicolumn{6}{|c|}{ GLM } \\
\hline & & & & Coefficient & SE & z & $P>|z|$ & \multicolumn{2}{|c|}{$[95 \% \mathrm{Cl}]$} \\
\hline$N Z$ & 15 & 63.3 & 9.647 & 4.142 & 4.070 & 1.02 & 0.309 & -3.836 & 12.120 \\
\hline None & 14 & 63.4 & 9.509 & 4.304 & 4.121 & 1.04 & 0.296 & -3.773 & 12.380 \\
\hline Constant & & & & 59.125 & 3.287 & 17.99 & 0.000 & 52.682 & 65.568 \\
\hline
\end{tabular}

CV denture preference was used as reference.

$\mathrm{GLM}=$ generalized linear model; $\mathrm{CV}=$ conventional denture; NZ = neutral zone denture; $\mathrm{SD}=$ standard deviation; $\mathrm{SE}=$ standard error; $\mathrm{z}=$ standard score; $\mathrm{Cl}=$ confidence interval.

Table 9 GLM Analysis of Denture Preference and Mean Years of Edentulousness

\begin{tabular}{|c|c|c|c|c|c|c|c|c|c|}
\hline \multirow{2}{*}{$\begin{array}{l}\text { Preference } \\
\text { CV }\end{array}$} & \multirow{2}{*}{$\frac{n}{8}$} & \multirow{2}{*}{$\begin{array}{c}\text { Mean period of } \\
\text { edentulousness } \\
(\mathrm{y})\end{array}$} & \multirow[b]{2}{*}{ SD } & \multicolumn{6}{|c|}{ GLM } \\
\hline & & & & Coefficient & SE & z & $P>|z|$ & [95 & \\
\hline NZ & 15 & 29.87 & 16.35 & -6.383 & 6.427 & -0.99 & 0.321 & -18.981 & 6.214 \\
\hline None & 14 & 29.18 & 15.79 & -7.071 & 6.507 & -1.09 & 0.277 & 19.824 & 5.681 \\
\hline Constant & & & & 36.250 & 5.190 & 6.98 & 0.000 & 26.077 & 46.423 \\
\hline
\end{tabular}

CV denture preference was used as reference.

$\mathrm{CV}=$ conventional denture; $\mathrm{NZ}=$ neutral zone denture; $\mathrm{SD}=$ standard deviation; $\mathrm{SE}=$ standard error; $\mathrm{z}=$ standard score; $\mathrm{Cl}=\mathrm{confidence}$ interval.

GLM relating denture preference and period of edentulousness. The mean period of edentulousness for the CV preference was 36.25 years. The mean periods of edentulousness for the NZ preference and for no preference were 6.38 and 7.07 years shorter, respectively. None of the relationships were statistically significant $(P>.05)$.

Of the 23 patients with a preference for a particular set, 20 provided feedback on the reason for their preference. The results are given in Table 10. 
Table 10 Frequency of Reasons a Particular Denture Was Preferred

\begin{tabular}{lcc}
\hline \multirow{2}{*}{ Reason } & \multicolumn{2}{c}{ Preference } \\
\cline { 2 - 3 } & NZ (n [\%]) & CV (n [\%]) \\
\hline Fit (including stability and retention) & $6(40)$ & $2(25)$ \\
Eating & $6(40)$ & $3(37)$ \\
Comfort & $4(27)$ & $3(37)$ \\
Speaking & $1(7)$ & $0(0)$ \\
Appearance & $0(0)$ & $0(0)$ \\
\hline
\end{tabular}

$\mathrm{NZ}=$ neutral zone denture; $\mathrm{CV}=$ conventional denture

\section{Discussion}

The first null hypothesis was that there is no patient preference for NZ or CV mandibular complete dentures. Statistically, the null hypothesis was accepted. No denture preference could be demonstrated among this group of patients. These results do not support results from previous trials. ${ }^{5-7}$

In a reported crossover trial with a small sample size $(n=10)$, no information on power calculation and delivery sequence was provided. ${ }^{7}$ In addition, patients without previous denture experience were asked to select their favorite denture after wearing each denture for only 2 weeks following the last postinsertion adjustment. All of them (100\%) preferred the NZ dentures. It is questionable whether 2 weeks is adequate to allow adaptation to CDs for edentulous patients without denture experience; this may have created bias toward the second denture because of the longer adaptation opportunity.

Mere replacement of CDs has a positive impact on OHRQoL and denture satisfaction. ${ }^{11}$ By implication, new dentures may be preferred regardless of whether they are functionally or anatomically made. However, judgment of the quality of CDs by clinicians does not necessarily correlate with patients' opinion of their dentures. ${ }^{12}$

The second null hypothesis was that patient variables were not associated with preference. With the exception of the relationship of NZ preference and OHIP-20 scores, this null hypothesis was accepted.

In terms of sex, no statistical difference was found among preference groups. No data in the literature was found associating sex to preferences between $\mathrm{CV}$ and NZ dentures.

To assess difference in impact on OHRQoL, denture preference was related to OHIP-20 scores. It could be assumed that difference in OHIP-20 scores would be related to denture preference. This was only true for those patients who preferred the NZ denture. The reason there was no agreement of preference with impact on OHRQoL for the remainder of the patients could be investigated further. No literature could be found relating $\mathrm{CV}$ or $\mathrm{NZ}$ denture preference to OHRQoL using the OHIP-20 instrument.

There is little literature associating NZ or CV denture preference and the quality of supporting tissue. In the present trial, mandibular tissue scores were found not to be a predictor for denture preference. Therefore, the present study could not support the findings of Barrenäs and Ödman, ${ }^{6}$ who found that patients with well-preserved ridges reported less difference between the two types of dentures and that the more resorbed the ridges, the stronger the indication for a NZ denture.

Adaptation to new dentures diminishes with age. ${ }^{8}$ Therefore, older patients may prefer dentures that are made to fit within a zone of minimal conflict with the surrounding musculature. However, this trial did not show a significant association between patient age and denture preference.

Likewise, period of edentulousness could not be related to denture preference. The mean period of edentulousness in the present study was long (31 years), and all patients had previous denture experience. The relationship of lack of denture experience and potential beneficial effect related to NZ dentures could be further explored in future clinical studies.

Better fit, comfort, and eating were the dominant reasons patients preferred a particular denture. This was mentioned twice as often for the NZ denture. This agrees to some extent with other studies, where stability and fit, ${ }^{5,7}$ less food, trapping, and easier chewing ${ }^{6,7}$ were identified as the reasons patients preferred the NZ denture over their existing or CV denture. In this study, some patients gave more than one reason while others did not give a reason. Appearance and speaking were not identified as reasons a certain denture was preferred. This does not support the results of previous studies. ${ }^{6,7}$ It has been reported that, for maxillary dentures, complaints are centered around esthetics and speech. ${ }^{13}$ The influence of the maxillary denture on preference was assumed to be minimal in this trial. First, the maxillary dentures were made to be identical for each pair of CV and NZ to eliminate the impact of difference in appearance. Second, appearance was never mentioned as a contributing factor for preference, and speech was mentioned only once.

This study was designed as a prospective withinsubject crossover trial in which each participant was exposed to a sequence of two interventions. The advantages of a crossover design is that patients act as their own control, smaller sample sizes are required, and preference can be established. Randomization of sequence of delivery was done by random draw by the patients (NZ or CV). A total of $20 \mathrm{CV}$ and $17 \mathrm{NZ}$ dentures were given first. The small difference in sequence 
was the result of the 95\% retention of patients in the trial. It was anticipated that some patients would not return for the second set of CDs, and the total number of patients, after power calculation determined a minimum number of 34 , was set at 40 . Patients wore each set of CDs for 8 weeks after the last recall visit. This period was previously suggested as satisfactory for establishing patient preference among different prostheses and is often used in prospective crossover trials dealing with the management of edentulousness. ${ }^{14}$ Nonetheless, a longer time frame to more robustly evaluate patient response outcomes should not be overlooked. All of the study patients came from a similar sociodemographic region and had similar levels of education. It has been reported that social and cultural norms, even political events to which populations are exposed, may shape behavior and perceptions of health for entire cohorts. Thus, caution should be used when comparing the results of this trial with results of studies using populations with different sociodemographic backgrounds.

Numerous publications note that patients' appraisal of the clinical competence of the clinician and a good patient-clinician relationship may play a more important role than prosthodontic factors in achieving positive treatment results. All patients in this study were managed by one clinician who was experienced in rehabilitating edentulous patients with CDs. Patients' appraisal of the skills of the clinician may have overruled patients' appraisal of the differences between the two interventions.

None of the patients suffered from orofacial motor disorders, this being an exclusion criterion for the trial. Therefore, no conclusions could be made on the influence of these variables on intervention preference. These issues could be further researched.

For this cohort of patients, no appraisal of prosthetic adaptive capacity was made. However, since no preference between the two interventions could be demonstrated, it is assumed that the difference in impact on PBOs is too small: adaptive patients will adapt to both interventions, maladaptive patients will not. For the latter group, other treatment interventions, such as implant-retained overdentures, need to be explored to improve PBO.

\section{Conclusions}

Within the limitations of this study, it can be concluded that there was no preference among patients for
$\mathrm{NZ}$ or CV mandibular complete dentures; there was no association between OHIP-20 scores and preference, except for NZ preference and OHIP-20 scores; and sex, quality of mandibular supporting tissue, PDI, age, and period of edentulousness were not predictors for denture preference.

\section{Acknowledgments}

The authors wish to thank Dr George Zarb for his assistance during manuscript review and the University of the Western Cape for financial support. This paper was presented before the South African Division of the International Association of Dental Research, Pretoria, South Africa, 3-4 September 2015. The authors reported no conflicts of interest related to this study.

\section{References}

1. American College of Prosthodontists. The glossary of prosthodontic terms. J Prosthet Dent 2005;94:10-92.

2. Beresin VE, Schiesser FJ. The neutral zone in complete dentures. J Prosthet Dent 1976;36:356-367.

3. Carlsson GE, Omar R. The future of complete dentures in oral rehabilitation. A critical review. J Oral Rehabil 2010;37:143-156.

4. Owen CP. Guidelines for a minimum acceptable protocol for the construction of complete dentures. Int J Prosthodont 2006:19:467-474.

5. Walsh JF, Walsh T. Muscle-formed complete mandibular dentures. J Prosthet Dent 1976;35:254-258.

6. Barrenäs L, Ödman P. Myodynamic and conventional construction of complete dentures: A comparative study of comfort and function. J Oral Rehabil 1989;16:457-465.

7. Fahmy FM, Kharat DU. A study of the importance of the neutral zone in complete dentures. J Prosthet Dent 1990;64:459-462.

8. Müller F. Interventions for edentate elders: What is the evidence? Gerodontology 2014;31(Suppl 1):44-51.

9. McGarry TJ, Nimmo A, Skiba JF, Ahlstrom RH, Smith CR, Koumjian $\mathrm{JH}$. Classification system for complete edentulism. The American College of Prosthodontics. J Prosthodont 1999;8:27-39.

10. Cagna DR, Massad JJ, Schiesser FJ. The neutral zone revisited: From historical concepts to modern application. J Prosthet Dent 2009;101:405-412.

11. Adam RZ, Geerts GA, Lalloo R. The impact of new complete dentures on oral health-related quality of life. SADJ 2007;62:264-266.

12. Heydecke G, Klemetti E, Awad MA, Lund JP, Feine JS. Relationship between prosthodontic evaluation and patient ratings of mandibular conventional and implant prostheses. Int J Prosthodont 2003;16:307-312.

13. Steele JG, Sanders AE, Slade GD, et al. How do age and tooth loss affect oral health impacts and quality of life? A study comparing two national samples. Community Dent Oral Epidemiol 2004;32:107-114.

14. de Grandmont $P$, Feine JS, Taché R, et al. Within-subject comparisons of implant-supported mandibular prostheses: Psycometric evaluation. J Dent Res 1994;73:1096-1104. 